\title{
HYBRID COMPOSITES OF SHORT KENAF AND ABELMOSCHUS ESCULENTUS FIBER-FLEXURAL PROPERTIES AND SEM ANALYSIS
}

\author{
K.Kishor Kumar'1, P.Ramesh Babu² , K. Rajanarender Reddy ${ }^{3}$ \\ ${ }^{1}$ MED, KITS-Warangal, India \\ 2Osmania University-Hyderabad, India \\ ${ }_{3}^{3}$ MED, KITS-Warangal, India \\ Email: 1kishor.kits@gmail.com
}

\begin{abstract}
.
Natural fibre reinforced composites is an emerging area in polymer science. Natural fibres have the advantages of low density, low cost, biodegradability. However, in development of these composites, the incompatibility of the fibres and poor resistance to moisture often reduce the potential of natural fibres and these drawbacks become critical issue. The present work study the flexural behaviour and morphology of short hybrid fiber reinforced natural composites, for this work Kenaf and abelmoschus esculentus plant fibers of $2 \mathrm{~mm} 4 \mathrm{~mm} 6 \mathrm{~mm}$ and $8 \mathrm{~mm}$ lengths are used to prepare the lamina. General purpose isopthalic resin is used for the present work. Flexural test and SEM analysis are conducted on these specimens according to the ASTM standards; from The results the composite with $4 \mathrm{~mm}$ fiber length has shown highest flexural strength of 97 MPA with superior morphological characteristics at the fractured surface. The morphology of the lamina is also studied in the present work.
\end{abstract}

Key words: Hybrid Natural fiber reinforced composites, flexural properties, SEM analysis.

\section{INTRODUCTION}

The concept of hybridization gives flexibility to the design engineer to tailor the material properties according to the requirements, which is one of the major advantages of the composites. Hybrid composites have long taken the attention of many researchers as a way to enhance mechanical properties of composites. Hybrid composites are more advanced composites as compared to the conventional FRP composites. They have more than one reinforcing phase and a single matrix phase or a single reinforcing phase with multiple matrix phases or multiple reinforcing and multiple matrix phases. They have better flexibility as compared to fibre reinforced composites. Normally it contains a high modulus fibre with a low modulus fibre. The high modulus fibre provides the stiffness and the load bearing qualities, whereas low modulus fibre makes the composite more damage tolerant and keeps the material costs low. The mechanical properties of hybrid composites can be varied by changing weight/volume ratios of fibre and resin, stacking sequence of different plies.

However, hybrid composites using natural fibers are less studied. And in such studies, the hybrid composite often consists of one natural fiber and one artificial fiber .The present work explains the effect of varying length and treatment of fibers on flexural and morphological properties of the hybrid composite

\section{LITERATURE REVIEW}

Nur Hafizah Bt Abd Khalidand Jamaludin Mohammad Yatim(2010) found that the treated fibers have lower average tensile strength than untreated fibers. Young's modulus of treated fibers have higher value than untreated fibers. Fiber with higher moisture content lead to lower average tensile strength.

D. Bachtiar, S.M. Sapuan and M.M. Hamdan(2010) found from their research that the maximum flexural strength $(96.71 \mathrm{MPa})$ of the composite is for the alkali treatment of $0.25 \mathrm{M}$ alkali solution and $1 \mathrm{hr}$ soaking time. The high concentration of the alkali treatment provides for increasing of the flexural modulus significantly it may be caused by the alkaline effect on fibers that increases their crystallinity.

\section{A. Materials \& Methods}

In the present work laminates are fabricated using two different plant fibres namely Abelmoschus Esculentus and hibiscus cannabinus as reinforcement and general 
purpose resin as matrix Abelmoschus Esculentus, known in many English speaking countries as ladies finger. The plant is cultivated in tropical, subtropical and warm temperate regions around the world.

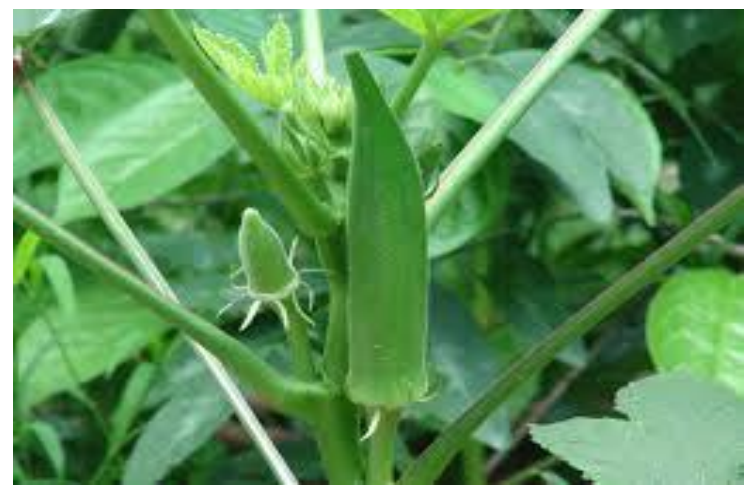

Fig. 1. Abelmoschus Esculentus

Hibiscus cannabinus is known as kenaf. The stalk of kenaf plant consists of two distinct fibre types. The outer fibre is called "BAST" and comprises roughly of the $40 \%$ stalk's dry weight. The white inner fibre is called "CORE" and comprises $60 \%$ stalk's dry weight. Kenaf fibres are extracted from the bast having a potential alternative as reinforcement in polymeric composites instead of synthetic fibres

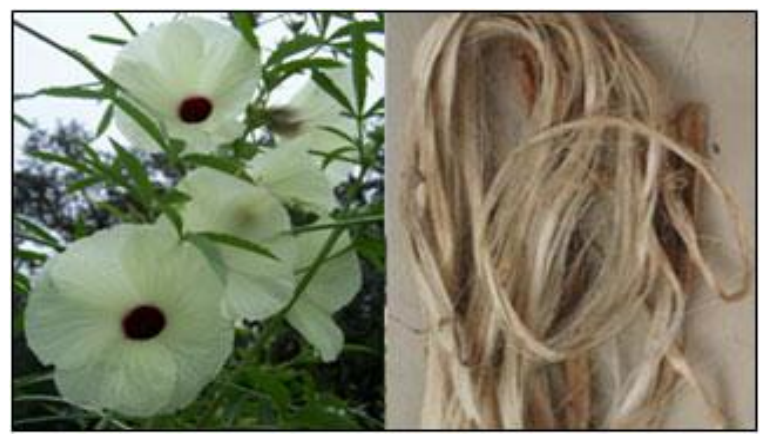

Fig. 2. Hibiscus Cannabinus and its fibres

\section{B.Preparation of Lamina:}

In the present work fibers are extracted from the plants of Abelmoschus Esculentus and hibiscus cannabinus that belong to the malvacea family using the process water retting, then the fibres are chemically treated with sodium hydroxide $(\mathrm{NaOH})$, it is an important factor because chemical treatment of fibres with $\mathrm{NaOH}$ will improve adhesion properties of fibers with resin and so as the mechanical properties. These fibres are chopped into $2 \mathrm{~mm}, 4 \mathrm{~mm}, 6 \mathrm{~mm}$ and $8 \mathrm{~mm}$ fibre lengths.

The laminas are prepared by hand layup technique. In the present work general purpose unsaturated polyester resin is taken along with $2 \%$ each of catalyst methyl ethyl ketone peroxide (MEKP) and accelerator cobalt naphtha-late. The weight ratio of resin to fiber is $30: 1$ is considered for the present work.

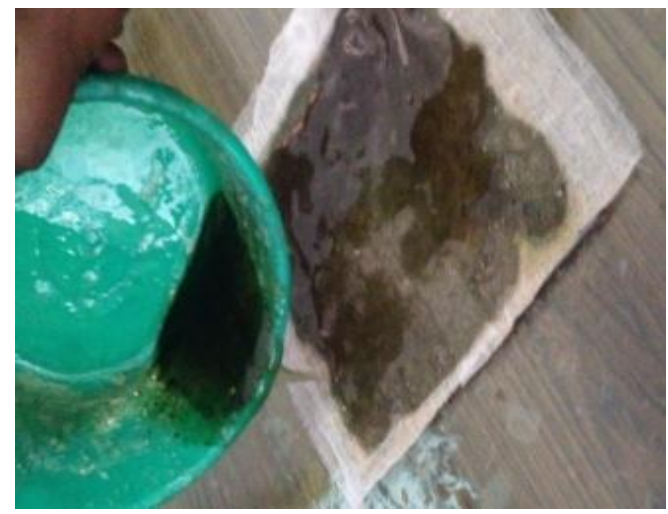

Fig. 3 Lamina preparation,

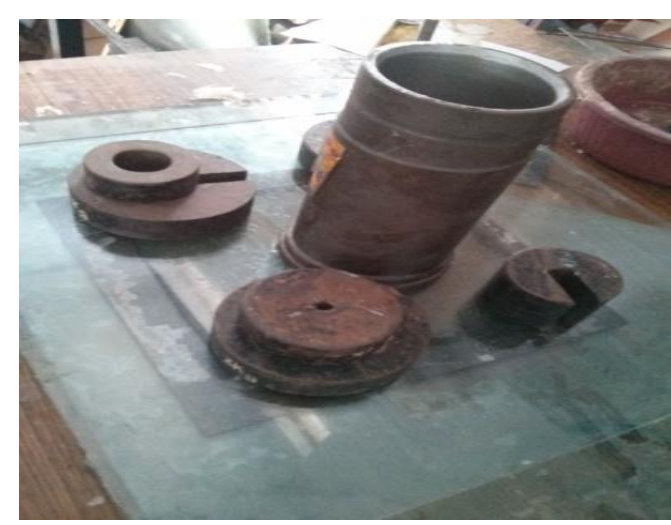

Fig.,4. Curing of Lamina

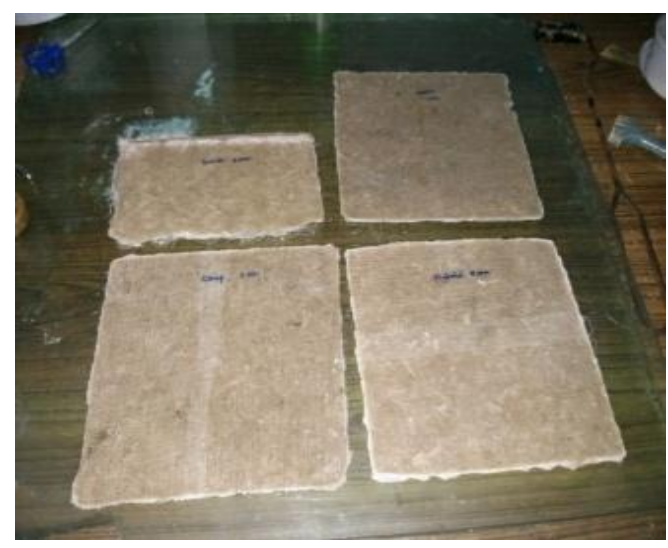

Fig.5 Laminas 


\section{C.Flexural Testing:}

Flexural strength is the ability of the material to withstand bending forces applied perpendicular to its longitudinal axis. Sometime it is referred as cross breaking strength where maximum stress developed when a bar-shaped test piece, acting as a simple beam, is subjected to a bending force perpendicular to the bar. As described in ASTM D790, three-point loading system applied on a supported beam was used for the present work. The specimen dimensions are taken as per ASTM standards. The bending stress is calculated from the measured load, as follows:

$$
\begin{aligned}
& \sigma_{\max }=3 \mathrm{PL} / 2 \mathrm{bd}^{2} \quad \text { Where, } \\
& \sigma_{\max }=\text { flexural strength, } \\
& P=\text { load at yield (max. Load), } \\
& L=\text { support span }(\mathrm{mm}), b=\text { width }(\mathrm{mm}), \\
& d=\text { thickness }(\mathrm{mm}) .
\end{aligned}
$$

From flexural test Flexural modulus or Modulus of elasticity is determined by the following equation

$$
\begin{aligned}
& E B=L^{3} P / 4 d^{3} b x \\
& E B=\text { flexural modulus }\left(N / \mathrm{mm}^{2}\right), \\
& L=\text { length of the flexural specimen }(\mathrm{mm}), \\
& P=\text { load at a given point on the load deflection } \\
& \text { curve }(\mathrm{N}), \\
& d=\text { thickness }(\mathrm{mm}), b=\text { width }(\mathrm{mm}), \\
& x=\text { deflection }(\mathrm{mm}) .
\end{aligned}
$$

Specimens for the Flexural Test are cut on a jig saw machine. The specimens are shown in the fig. 5.

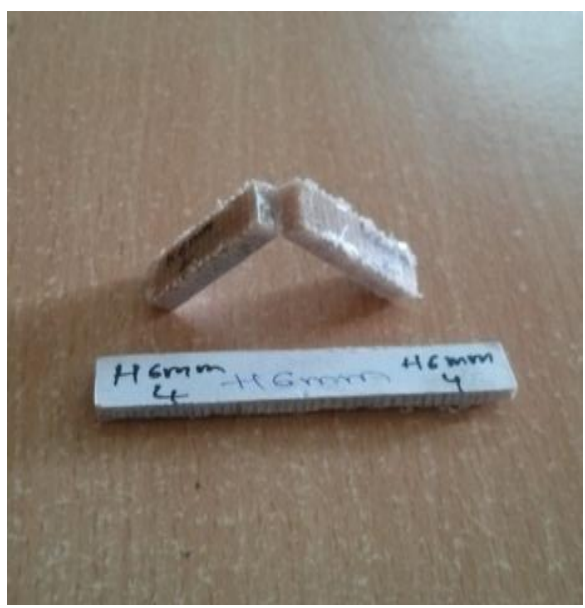

Fig .6. Flexural Specimen

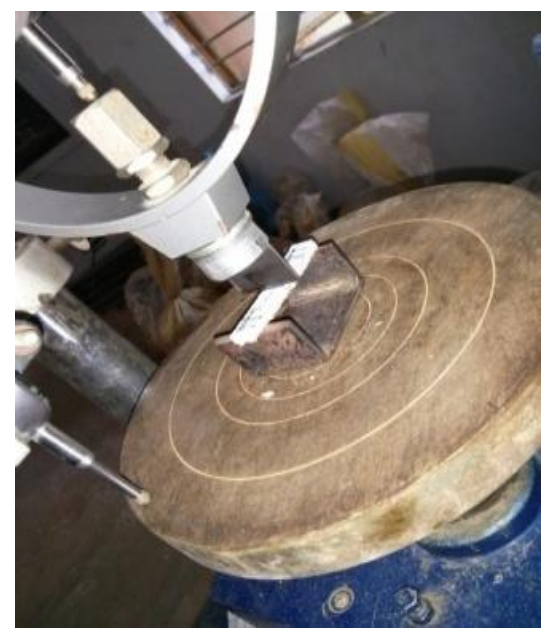

Fig .7. Flexural Test Setup

\section{Scanning Electron Microscopy:}

The Scanning Electron Microscopy was conducted on the fractured surface of the flexural test specimen to find the fiber matrix interfacial adhesion. The test was conducted in various magnifications ranging from $50 \mathrm{x}$ to $3000 x$. This test was performed in JSW steel plant on HitachiS-3400N scanning electron microscope and fig shows the test setup.

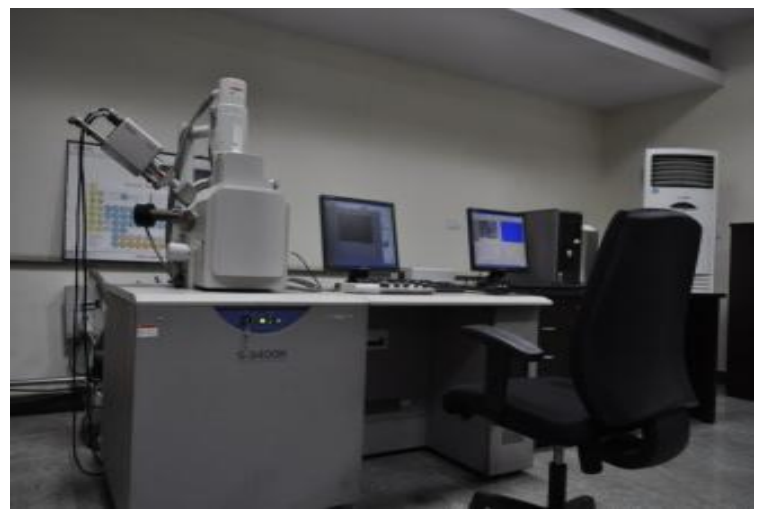

Fig .8. Hitachi S-3400 scanning electron microscope

\section{RESULTS AND DISCUSSIONS:}

$\mathrm{H} 2 \quad \mathrm{H} 4 \quad \mathrm{H} 6 \quad \mathrm{H} 8-$ hybrid composite with $2 \mathrm{~mm}, 4 \mathrm{~mm}, 6 \mathrm{~mm}, 8 \mathrm{~mm}$ as fiber length.

$\mathrm{K} 4 \mathrm{~K} 6$-composite with only kenaf $4 \mathrm{~mm}, 6 \mathrm{~mm}$ as the fiber length.

B8 -composite with only Abelmoschus Esculentus $8 \mathrm{~mm}$ as the fiber length. 


\section{Flexural test}

It is clear from the fig 8 that $\mathrm{H} 4$ has got the highest flexural strength $96.85 \mathrm{Mpa}$ and it is also clear that hybrid composites i.e.H4 $\mathrm{H} 6 \mathrm{H} 8$ have more flexural strength than un hybrid composites i.e. K4 K6 B8.

From the graphs we can interpret that composite with kenaf fiber as reinforcement has more flexural modulus than composite with ABELMOSCHUS ESCULENTUS as the reinforcement therefore kenaf is the high modulus fiber and by stacking kenaf at extreme surfaces and Abelmoschus Esculentus in between kenaf fibers flexural strength can be increased to a good extent and because of combination of high modulus fiber with low modulus fiber flexural strength of all hybrid composites have been more than single fiber reinforced composites.

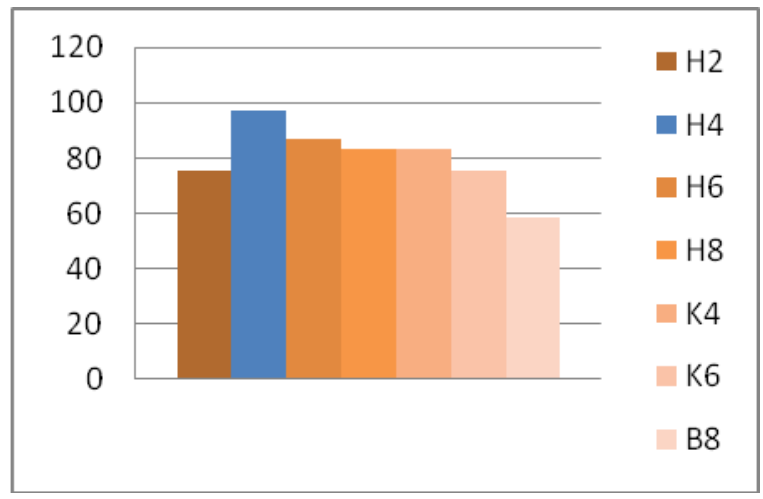

Fig .9. Graph For Flexural Strength

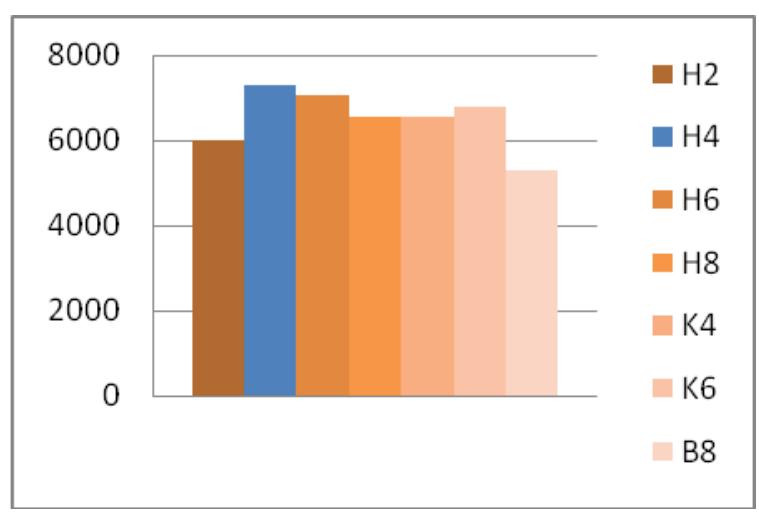

Fig .10. Graph For Flexural Modulus

Sem Analysis:

Figures below show the SEM images of fractured surface of $2 \mathrm{~mm} 4 \mathrm{~mm} 6 \mathrm{~mm} 8 \mathrm{~mm}$ Hybrid Natural Short FRP Flexural specimen at a magnification of $100 x$

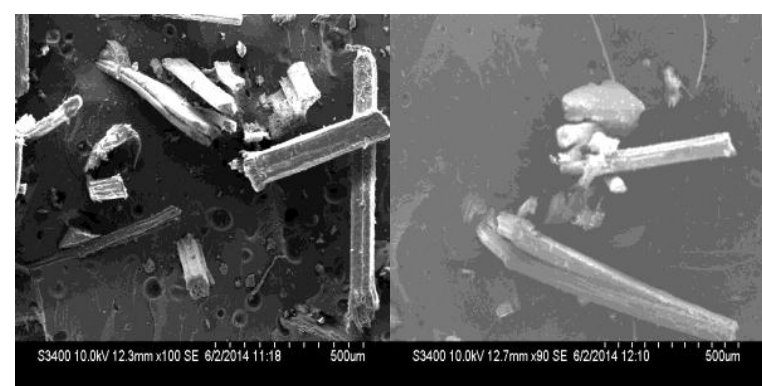

Fig .11. Fractured surface of $\mathrm{H} 2 \mathrm{~mm}, 4 \mathrm{~mm}$

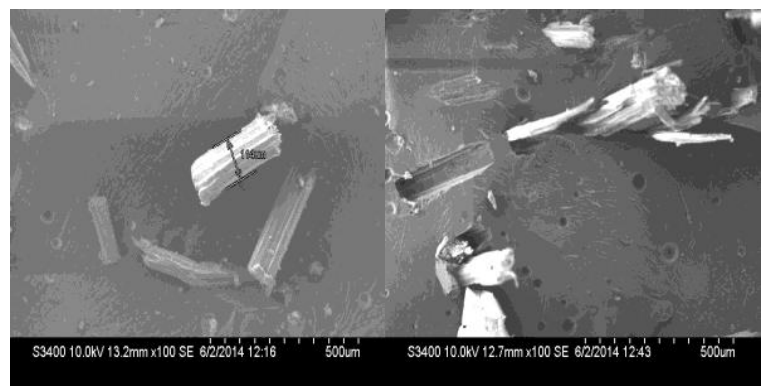

Fig .12. Fractured Surface $\mathrm{H} 4 \mathrm{~mm}, 8 \mathrm{~mm}$

Figures show the morphology of the fracture surface of the fibre reinforced hybrid composites for different fiber lengths. The weak bonding between fibre and matrix is indicated by holes as a result of the pull-out of the fibre from matrix locking. And the good interfacial bonding between the fibre and matrix is indicated by the existence of the fibre on the matrix although the composites break after loading can be verified from the value of flexural strength from the experiment. The sample with less flexural strength is indicated by the amount of holes which is much more than that of the other sample with higher flexural strength. The sample with $4 \mathrm{~mm}$ as fiber length shows good interfacial bonding as indicated by the presence of fewer holes in the fracture surface.

\section{CONCLUSIONS}

Short natural fiber reinforced hybrid composites have been successfully prepared with kenaf in conjunction with ABELMOSCHUS ESCULENTUS as reinforcement with $2 \mathrm{~mm}, 4 \mathrm{~mm}, 6 \mathrm{~mm}, 8 \mathrm{~mm}$ as the fiber lengths and polyester resin as the matrix, and these composites are tested for flexural properties according to the ASTM standards.

It can be concluded that a maximum flexural strength of 96.85MPA and maximum flexural modulus of 7284.34MPA is for the composite $\mathrm{H} 4$. There is an increase of $12.2 \%$ in flexural strength when length of fiber 
.decreased from $8 \mathrm{~mm}$ to $4 \mathrm{~mm}$ i.e. $\mathrm{H} 4$ has $12.2 \%$ more flexural strength than $\mathrm{H} 8 . \mathrm{H} 6$ has $14.9 \%$ more flexural strength than $\mathrm{K} 6$ which purely shows how hybridization helps in increasing the strength of the natural composites; $\mathrm{H} 2$ has $11.313 \%$ more flexural modulus than $\mathrm{H} 8$ natural composites; $\mathrm{H} 2$ has $11.313 \%$ more flexural modulus than $\mathrm{H} 8$. $\mathrm{H} 6$ has $14.9 \%$ more flexural strength than $\mathrm{K} 6$ which purely shows how hybridization helps in increasing the strength of the natural composites; $\mathrm{H} 2$ has $11.313 \%$ more flexural modulus than $\mathrm{H} 8$.

Table 2. Flexural Properties Different Lamina

\begin{tabular}{|l|c|c|c|c|c|c|c|}
\hline SPECIMENS & H2 & H4 & H6 & H8 & K4 & K6 & B8 \\
\hline $\begin{array}{l}\text { FLEXURAL } \\
\text { STRENGTH } \\
\left(\mathrm{N} / \mathrm{mm}^{2}\right)\end{array}$ & 75.146 & 96.85 & 78.48 & 91.845 & 83.496 & 75.146 & 58.447 \\
\hline $\begin{array}{l}\text { FLEXURAL } \\
\text { MODULUS } \\
\left(\mathrm{N} / \mathrm{mm}^{2}\right)\end{array}$ & 5984.09 & 7284.34 & 5902.82 & 6544.01 & 7064.55 & 6781.97 & 5274.87 \\
\hline
\end{tabular}

\section{ACKNOWLEDGEMENT}

We thank Mr Manohar Namani working in Product Development Team Product Design \& Quality Control from JSW steel plant Ballari who has helped us in performing the SEM analysis.

\section{REFERENCES}

[1] Elisangela Corradini, Syed H. Imam, JoseÁ. M. Agnelli, Luiz H. C. Mattoso,(2009) "Effect Of Coconut, Sisal And Jute Fibers On The Properties Of Starch/Gluten/Glycerol Matrix". Journal of Polymer Environment vol no: $(17,17): 1-9$.

[2] D. Bachtiar, S.M. Sapuan and M.M. Hamdan,(2010) "Flexural Properties of Alkaline Treated Sugar Palm Fibre Reinforced Epoxy Composites". International Journal of Automotive and Mechanical Engineering (IJAME). Volume 1, 79-90.
[3] Girisha.C, Sanjeevamurthy, Gunti Rangasrinivas( 2012),"Tensile Properties of Natural Fiber Reinforced Epoxyhybrid Composites". International Journal of Modern Engineering Research (IJMER). Vol.2, Issue.2, 471-474.

[4] K.Kishor Kumar Dr K.Raja Narender Reddy Ch.Karunakar Guna Saketh Harika Sai Kumar, (2013) "Flexural Properties Of Green Composites Reinforced With Short Kenaf And Thespesia Lampus Fibers". Int.Conf. on Advanced Materials, Manufacturing, Management \& Thermal Sciences-, 04 ISBN13 978-81-926304- 0-3.

[5] K. Kishor Kumar, P. Ramesh Babu and K. Raja Narender Reddy Evaluation of Flexural and Tensile Properties of Short Kenaf Fiber Reinforced Green Composites International Journal of Advanced Mechanical Engineering. ISSN 22503234 Volume 4, Number 4 (2014), pp. $371-380$ 